\title{
Sous-Parsat
}

\section{Jean Lelache}

\section{OpenEdition \\ Journals}

Édition électronique

URL : http://journals.openedition.org/adlfi/5100

ISSN : 2114-0502

Éditeur

Ministère de la culture

Référence électronique

Jean Lelache, "Sous-Parsat », ADLFI. Archéologie de la France - Informations [En ligne], Limousin, mis en ligne le 01 mars 2006, consulté le 01 mai 2019. URL : http://journals.openedition.org/adlfi/5100

Ce document a été généré automatiquement le 1 mai 2019.

(c) Ministère de la Culture et de la Communication, CNRS 


\title{
Sous-Parsat
}

\author{
Jean Lelache
}

Identifiant de l'opération archéologique : 2664

Date de l'opération : 2006 (PR)

1 Pour la première année de prospection, nous nous sommes fixé trois axes de travail :

2 - analyser les fiches précédemment établies et éventuellement les améliorer ;

3 - définir une méthodologie de travail (enquête orale, étude des éléments de toponymie disponibles, analyse des photos aériennes de l'IGN, aborder la géomorphologie de la commune et de ses environs immédiats et constituer une base de données, etc.);

4 - commencer la prospection de terrain - en profitant des travaux agricoles donnant très temporairementune vision du mobilier de surface - en relation avec les personnes représentant la « mémoire » locale.

5 Cela nous a permis d'apprécier la richesse historique que nous apporté la présence de la voie romaine et, l'un étant sans doute relié à l'autre, la présence de la forêt de Pognat.

6 Cela nous a aussi permis de constater que si « Château Bourcy » faisait autrefois partie de la paroisse de Sous-Parsat, il était maintenant sur la commune d'Ahun et qu'il était utile de s'informer sur les zones de voisinage immédiat.

7 Pour cette année, quatre fiches peuvent être proposées sur des points qui sortent, par leur fiabilité, de l'ensemble des observations ponctuelles faites: cippe funéraire de la Gardanèche, hache et outils en silex (du Grand-Pressigny ?) de Pognat, cloche du XVI ${ }^{\mathrm{e}} \mathrm{s}$. de l'église de Mareilles, moulin de Sous-Parsat.

8 Pour l'année prochaine, outre la forêt de Pognat, nous continuerons également à étudier les microtoponymes qui posent parfois question: les Palisses, Blaudeix, Vivier, Ramerouge, Le Pré Rouge, Les Bussières, Château Milan, Château Mory...

9 LELACHE Jean 
INDEX

Thèmes : analyse documentaire, base de données, cippe, cloche, église, forêt d'arbres, géomorphologie, hache, industrie lithique, méthodologie, moulin, outil, paroisse, prospection, silex, sources orales, toponymie, voie romaine

Index chronologique : Empire romain, Moyen Âge*, XVIe siècle apr. J.-C.

operation Prospection (PR), Prospection diachronique (PRD)

Index géographique : Limousin, Creuse (23), Sous-Parsat

\section{AUTEURS}

JEAN LELACHE

Bénévole 